\title{
EVOLUÇÃO DAS POLÍTICAS CONSERVACIONISTAS E A CRIAÇÃO DE UNIDADES DE CONSERVAÇÃO NO VALE DO ITAJAÍ-SC
}

\author{
M. S. GARROTE*, V. DAMBROWSKI, G. F. DOS SANTOS e J. G. AMARO \\ Universidade Regional de Blumenau - FURB \\ martin_stabelgarrote@yahoo.com.br \\ Submetido 15/04/2016 - Aceito 14/01/2018 \\ DOI: $10.15628 /$ holos.2017.4428
}

\section{RESUMO}

No Brasil o processo de ocupação e uso do solo causou uma drástica redução da cobertura florestal do Bioma Mata Atlântica. A principal política de conservação foi a criação de Unidades de Conservação (UCs). A pesquisa analisou o processo de criação das UCs no Vale do Itajaí, Santa Catarina, Brasil. Identificaram-se 27 UCs, 3 na esfera federal, 3 estaduais e 21 municipais. Destas 5 antecederam a ECO 92. As UCS foram criadas com objetivos específicos por questões
\end{abstract}

locais, como no caso da Reserva Biológica da Canela Preta (1980) e do Sassafrás (1977), para proteger espécies exploradas e ameaçadas, e a Floresta Nacional de Ibirama (1965) para a produção e distribuição de mudas nativas e exóticas para reposição das florestas exploradas. Após a ECO 92 foram criadas 22 UCs no Vale do Itajaí, convergindo com as políticas nacionais de conservação.

PALAVRAS-CHAVE: política conservacionista, unidades de conservação, Vale do Itajaí, Santa Catarina.

\section{EVOLUTION OF THE CONSERVATIONIST POLICIES AND THE CREATION OF THE CONSERVATIONAL UNITS IN THE ITAJAÍ VALLEY, SANTA CATARINA STATE, BRAZIL}

\begin{abstract}
In Brazil the process of the occupation and the use of the soil has caused a drastic reduction of the Atlantic Forest Biome. The main conservation policy was the creation of the conservational units. The research analyzed the process of creation in the Itajai Valley, Santa Catarina State, Brazil, where were identified 27 conservational units, being 3 federal, 3 state and 21 in the municipality spheres. Of these 5 were created before ECO 92 . The conservational units were created
\end{abstract}

with specific objectives according to the local questions, as in the case of the Biologic Reserve of Canela Preta (1980) and the Sassafras (1977), to protect the exploited and endangered species, and the National Forest of Ibirama (1965) to the production and distribution of native and exotic seedlings in order to restore the exploited forests. Of the 27 conservational units in the Itajaí Valley, 22 were created after ECO 92, converging with the national policies of conservation.

KEYWORDS: Conservationist policy, conservational units, Itajaí valley, Santa Catarina State. 


\section{INTRODUÇÃO}

No Brasil até meados do século $X X$ as iniciativas de preservação ou conservação não caminharam efetivamente, a não ser nos casos onde o pano de fundo era o interesse em algum elemento da biodiversidade que passaria a ser usado como um recurso econômico. Havia um entendimento utilitarista nas intenções de preservar para o futuro. Em simetria com as políticas mundiais preocupadas com o modelo de desenvolvimento, e com as novas interpretações de como deveriam ser os parques, principalmente a partir de Yellowstone (Estados Unidos), o crescimento econômico e seus limites, a natureza no país passou a ser agenda política, acrescentando aos interesses políticos salvaguardar a beleza da flora e fauna brasileira (Dean, 1996). Até a década de 1990 não havia uma preocupação com a conservação da biodiversidade, e foi a partir da ECO 92, Conferencia Mundial do Meio Ambiente realizada no Rio de Janeiro, que efetivamente com a Convenção da Diversidade Biológica, as ideias de áreas protegidas para conservação da biodiversidade passam a ser pauta da agenda política. A partir da Lei que cria o Sistema Nacional de Unidades de Conservação da Natureza - SNUC, a criação de Unidades de Conservação tornou-se uma das principais políticas para conservar a natureza e os recursos naturais.

No Vale do Itajaí, Santa Catarina, as iniciativas de criação de áreas de conservação já estão presentes desde o início da colonização por europeus, e posteriormente atreladas às políticas nacionais, estaduais e municipais. Grande parte delas surge com o olhar da comunidade voltada para a conservação de remanescentes da exploração e uso agrícola ou industrial, iniciado no final do século XIX, agravando-se principalmente após a década de 1970. Um dos principais motivadores para se pensar a conservação na região foram as consequências visíveis no ambiente causadas pelas atividades da extração vegetal, caça e indústria (Bacca, 2008).

O intuito da pesquisa foi compreender o processo histórico de criação de Unidades de Conservação no Brasil, Santa Catarina, e especialmente no Vale do Itajaí. Analisa o processo de criação das UCs (Nacionais, Estaduais e Municipais) presentes no referido vale, identificando a motivação e objetivos das UCs.

\section{O TERRITÓRIO E A ABORDAGEM TEÓRICA METODOLÓGICA}

A área de estudo corresponde à bacia hidrográfica do Itajaí (Figura 1), Santa Catarina, sul do Brasil. É uma área de $15.500 \mathrm{~km}^{2}$, possuindo um relevo que a caracteriza em alto, médio e baixo vale. Seus cursos de água somam 24.171 quilômetros de extensão, sendo o principal o Rio Itajaí Açu. Antes da colonização europeia predominava a cobertura de Floresta Ombrófila Densa, ocorrendo por todo o litoral, alargando-se para o interior ocupando altitudes de 800 metros. A composição de vales profundos amplia a densidade florestal, com árvores de 30 a 45 metros de altura, formando um sistema copal fechado, com espécimes considerados excelentes para o uso como recurso econômico na cultura do colonizador (Siebert, 1997).

O recorte temporal corresponde às interpretações das fontes analisadas no período de 1850 até o início do século XXI. Sobre essa delimitação foi realizada uma pesquisa de base, 
descritiva de caráter historiográfico, com levantamento de dados secundários e análise com a base teórica do que foi denominado por Emmanuel Le Roy Ladurie em 1974 de Histoire et environnement ou História Ambiental (Worster, 1991).

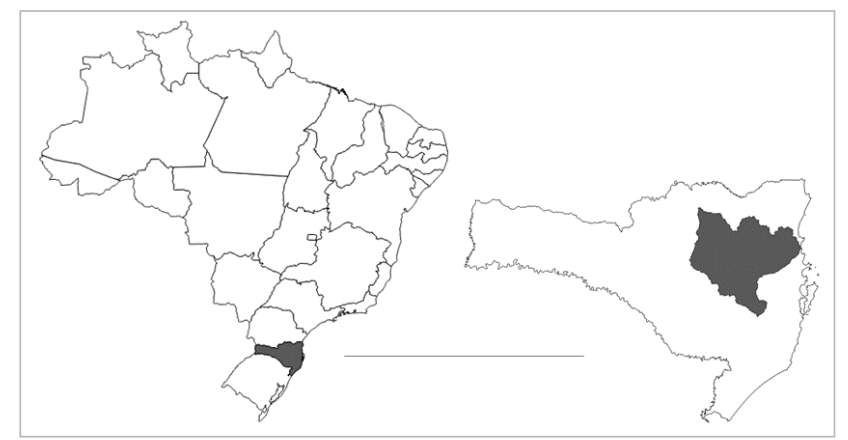

Figura 1: Localização da Bacia do Itajaí, estado de Santa Catarina, sul do Brasil. Fonte: Elaboração própria.

A História Ambiental deve ser feita em três níveis de informações associados. O primeiro trata do entendimento da natureza propriamente dita, tal como se organizou e funcionou no passado, incluindo aspectos orgânicos e inorgânicos da natureza, e como se configura no presente. No segundo nível se analisa o domínio socioeconômico e sua interação e interdependência com o ambiente. Trata-se de compreender as relações sociais que brotam das interações e interdependências nos diversos modos que os povos criam e produzem bens a partir de recursos naturais. No terceiro nível busca-se a compreensão da interação mental e intelectual da produção humana, as percepções, valores éticos, leis, mitos e demais estruturas de significação sobre a natureza (Worster, 1991).

É essencial fazer uma história ligando esses três níveis, o que é uma tarefa difícil, e muitas vezes, ocorre que um nível é mais destacado que outro, mas esta forma de investigar a História deve considerar a sociedade humana inclusa nos sistemas naturais. Assim, o fazer História Ambiental é analisar o processo histórico considerando os fatores físicos, químicos e biológicos do espaço, ou território que se analisa, observando como se deu na diversidade sociocultural as transformações dos elementos naturais em recursos econômicos, avaliando as formas de usos e necessidades, e as consequências originadas no quadro natural e social. Analisa-se também o pensamento sobre o que é o natural, suas representações e codificações simbólicas, que estabelecem o comportamento sobre o ambiente, compreendendo como se dá as interações, dependências e interdependências (Pádua, 2010).

Com o aporte teórico e metodológico da História Ambiental, a pesquisa se deu através dos caminhos e fontes tradicionais do ofício do historiador. Inicialmente foram levantados dados documentais, bibliográficos e digitais em bancos de dados governamental onde foi possível estabelecer uma revisão bibliográfica sobre a cronologia do desenvolvimento das políticas públicas sobre as Unidades de Conservação no Brasil, Santa Catarina e no Vale do Itajaí, dados coletados com o ICMBio - Instituto Chico Mendes de Conservação da Biodiversidade (Blumenau), FATMA Fundação do Meio Ambiente de Santa Catarina, secretarias municipais de meio ambiente de Blumenau, Itajaí e Timbó, e base de dados disponíveis na web. Os dados propiciaram organizar uma lista das UCS, suas documentações legais, como leis, decretos e planos de manejo. $\mathrm{Na}$ 
segunda etapa da pesquisa os dados coletados foram organizados e tabulados, realizando leituras, classificações e comparações das informações encontradas, identificando os resultados dos objetivos propostos.

\section{$3 \quad$ RESULTADOS E DISCUSSÃO}

\subsection{A proteção de áreas naturais}

Desde o processo de desenvolvimento agrícola no final do Neolítico os grupos humanos passaram a se preocupar com a manutenção da natureza, resguardando áreas para a renovação da floresta para posteriormente usar o solo fertilizado naturalmente (Mazoyer \& Roudart, 2010). A ideia de conservação se dava através do comportamento referente ao modo de vida, do modus vivendi, que as sociedades estabeleciam no ambiente. 0 desenvolvimento da institucionalização do fenômeno religioso em cada sociedade passou também a expressar a forma como se dava a interação e interdependência com a natureza (Singer, 1998). No caso da cultura religiosa ocidental, a partir do século XVII a conceituação do que é natureza foi depreciada, e as mentes das pessoas formatadas para aceitarem e viverem a ideia de que tudo no ambiente é criação divina, e que é feita para servir à sua melhor criatura, os humanos. A natureza passa a ser dominada e estar a serviço do desenvolvimento da empreitada humana, no surgimento do mercado, da indústria e do capital, e da sociedade moderna (Vianna, 2008).

O predomínio humano sobre a natureza passou a estar comprometido em conhecê-la para usá-la. E é nesse sentido que as áreas estratégicas para a sobrevivência das sociedades são salvaguardadas, e em muitos casos motivadas pelo avanço exploratório humano. Na Europa medieval criaram-se áreas protegidas com o intuito de preservar habitats da fauna silvestre e florestas, tendo a conservação aqui atributo de utilidade, como parques de caça e de reservas de lenha, de remédio e de outros recursos naturais administrados por nobres, e em grande parte por reis. Era normal nas propriedades feudais a conservação de florestas para a obtenção de lenha e de manter os mananciais de água limpos para consumo e uso agrícola (Morsello, 2001).

Com a modernidade a natureza é concebida ainda mais como um bem utilitário, e desenvolve-se uma visão que é difundida com a cultura europeia, o pensamento antropocentrista, surgindo nos sujeitos um comportamento cada vez mais centrado na obtenção da vantagem com o uso dos recursos naturais. Nesse sentido ocorre uma interação do humano sobre o mundo natural totalmente valorado e utilitarista. Tida como infinita, mas notada como finita com sua escassez, a natureza preocupa a sociedade no momento da sua falta nos processos de transformação em mercadorias (Vianna, 2008).

No intuito de preservar a matéria-prima, o mundo industrializado adotou a criação de parques ou reservas como uma das principais políticas/estratégias para resguardar áreas com determinada riqueza ou interesse econômico. No início, a preocupação em resguardar áreas naturais estava, principalmente, em criar reservas de matéria-prima. "Essa visão, matéria-prima para o edifício humanista moderno, estimula as ideias sobre a capacidade e necessidade da humanidade de controlar a natureza e legitima os direitos daquela sobre esta" (Vianna, 2008, p.137). 
Conforme Vianna (2008), a economia brasileira de caráter colonial atendia demandas externas. A natureza era vista como uma fonte de matéria-prima para o sistema produtivo que se instalava na Europa ao se beneficiar das colônias. Na transição para a modernidade alguns fatos traduzem a preocupação da conservação da natureza no país. Dean (1996), afirmou que em 1608 no Rio de Janeiro, por exemplo, aconteceram manifestações para barrar o desmatamento e ocupação humana em áreas de mananciais. Outro fato foi a proibição do corte da mata de mangues decretada por $\mathrm{D}$. João $\mathrm{VI}$, com a finalidade de privar a coroa o uso e extração do tanino. Assim como as proibições de corte florestal por Maurício de Nassau com o intuito de preservar os recursos para uso no futuro.

Pádua (2010) descreveu que no Brasil a preocupação ambiental no sentido de guardar áreas intensificou-se a partir do século XVIII. Os pensadores da época analisavam formas de resguardar os recursos para o desenvolvimento, como a conservação de áreas de nascentes para o abastecimento hídrico das cidades, e de áreas de interesse mineralógico e florestal.

O período que antecede o império até o século XX, conforme assinalado por Dean (1996), o processo civilizador é marcado pelo caráter colonizador de exploração da natureza. Isto expressa uma total miopia no conhecimento e uso do mundo natural do território brasileiro, e apenas aproveitaram-se os recursos que representam usos do mundo material europeu. O processo de exploração aniquila a biodiversidade e a floresta, assim como a sabedoria dos povos que aqui já habitavam.

Com a chegada da família real no século XIX é implantada uma política ambiental de estudar o que havia restado da condição da natureza depois da espoliação colonial. Assim é realizada uma transferência de conhecimento científico para a Europa atrelado às instituições criadas no Brasil, como o Jardim Botânico, e diversos museus e institutos. O objetivo é conhecer com a ciência europeia o território brasileiro. Nessa onda, diversos cientistas se estabeleceram no território nacional e executaram descrições da natureza (Dean, 1996).

\subsection{Preocupação da preservação da natureza}

No mundo a preocupação com a natureza estava pautada sobre o entendimento de evitar o mal-uso ou da exploração excessiva por populações urbanas e do poder público, com a preocupação de guardar esses recursos em áreas protegidas para posterior uso, como parques de caça. Não havia no pensamento da época a preocupação de conservar a natureza como apontava o pensamento ambiental estadunidense, que criava parques no intuito de mantê-los intocados do processo civilizador, permitindo a complexidade da biodiversidade fluir (Vianna, 2008).

Dean (1996) apontou que diferente do pensamento conservacionista estadunidense, no sentido utilitarista, no século XIX as iniciativas de criação de áreas no Brasil se deram em grande parte pela iniciativa privada, principalmente pelas indústrias do Sudeste. Uma das principais preocupações era o reflorestamento para o uso da lenha, pois esta matéria prima fomenta a industrialização do país, e não o carvão mineral como na Inglaterra e Alemanha. As florestas brasileiras alimentaram as caldeiras da indústria de exportação da natureza para a Europa. As iniciativas do poder público em criar áreas de conservação foram raras (Dean, 1996). 
Uma das iniciativas que preconizaram o início da política de parques no país é a de Manuel Gomes Archer de reflorestar a Serra da Tijuca. Utilizada no passado para o plantio de café, e totalmente desflorestado, forma o que hoje constitui o Parque da Tijuca no Rio de Janeiro. Outra iniciativa foi a do botânico do Museu Nacional, o senhor Landislau de Souza Mello Neto, que chamou atenção da comunidade científica com seus resultados do estudo de plantas ainda existentes nas florestas e nos conhecimentos dos povos brasileiros, com finalidade farmacêutica e industrial. O intuito de salvaguardar para uso medicinal ou industrial promove a criação de reservas florestais para estudos e pesquisas. "Neto criou uma rede brasileira de correspondentes, que incluía o eminente cientista imigrante Fritz Muller, primeiro defensor público de Darwin; Charles Hartt; Henri Gorceix, diretor da Escola de Minas, e Hermann Von Ihering [...] (Dean, 1996, p. 245).

Destacam-se também as contribuições do botânico Alberto Loefgren que compõem a Expedição Geológica e Geográfica no país. "Seus estudos sobre espécies de árvores econômicas e seus cálculos sobre chuvas e temperaturas o levaram a crer que o desmatamento estava provocando mudanças climáticas, e que o reflorestamento era o remédio necessário". Seus comentários nos jornais, participação em clubes de conservação produziram outra compreensão na classe média paulista e carioca, e assim na política nacional. Os republicanos e liberais queriam modernizar a política, e a inclusão da conservação atinava com a mentalidade de políticas de conservação de outros países. Loefgren sugeria na transição para o século XX a criação de um código florestal que "[...] poderia garantir a conservação de florestas necessárias e proteger os cursos d'agua, solo e microclimas, e poderia por um fim à importação de madeiras, possibilitando posteriormente sua exploração". Loefgren também teve a ideia do Dia da Árvore, que ocorreu inicialmente em Araras em 1902 com a presença do presidente e vice-presidente da república (Dean, 1996, p. 248).

Através do pensamento conservacionista estadunidense, difunde-se no Brasil a ideia de criação de parques para preservar belezas cênicas naturais, flora e fauna, e até discute-se a presença humana e seu papel na biodiversidade. Nesse sentido, conforme Millano (2001), um marco no processo de criação de áreas de preservação foi a criação do Parque Nacional de Yellowstone, em 1872, nos Estados Unidos. A partir deste parque inclui-se na agenda dos fatores que motivam a criação de parques, a questão da conservação ambiental para guardar belezas naturais. O modelo de parque e a interpretação sobre a sua utilidade possibilitou no pensamento político brasileiro a inserção de uma ideia diferente de parques, mas esse foi um processo lento, com poucos exemplos que saíram do utilitarismo da natureza (Vianna, 2008).

De acordo com o descrito por Drummond (2010), a partir do final século XIX o país intensifica as políticas de conservação de áreas públicas (Federais Estaduais e Municipais). A partir da criação do Yellowstone nos EUA, a intenção da criação de áreas protegidas deixou de ter como fundo apenas o interesse econômico, inclinando para a conservação de diferentes formas. Fato que refletiu com políticas que fizeram surgir no país diversos parques, reservas, florestas nacionais, estações biológicas e etc.

No Brasil algumas iniciativas acompanharam o embalo da política desenvolvida a partir do Yellowstone. Em 1876 o engenheiro André Rebouças defendia a ideia de criação de dois parques nacionais nos moldes dos parques estadunidenses, um na llha do Bananal no rio Araguaia, e outro 
em Sete Quedas, rio Paraná. As aspirações de Rebouças, mais tarde em 1959, elucidariam o surgimento do Parque Nacional do Araguaia, e em 1961 o Parque Nacional das Sete Quedas, posteriormente inundado pelo lago da barragem da Usina de Itaipu (Drummond, 2010).

No início do século XX, o botânico sueco Alberto Loefgren estabeleceu em terras do governo a Estação Biológica de Itatiaia, tendo como finalidade a preservação e a continuidade dos estudos realizados pelos pesquisadores do Jardim Botânico e Museu Nacional do Rio de Janeiro, área que mais tarde daria início à criação do Parque Nacional do Itatiaia. Outra iniciativa foi a do alemão Herman Von Ihering que em 1909 estabeleceu no alto da Serra do Mar em São Paulo a Estação Biológica Alto da Serra, tendo como objetivo a preservação, a visitação e a realização de estudos científicos (Drummond, 2010).

No Brasil, diferente do estado norte americano, não havia capital para investir na criação de áreas de conservação, e no desenvolver da primeira metade do século $X X$, as questões ambientais representavam barreiras para o desenvolvimento (Dean, 1996). A criação de parques no Brasil foi inicialmente pensada no intuito de conservar os recursos naturais, fontes de matériasprimas. Algumas áreas foram estabelecidas com interesse da preservação terrestre ou aquática, com características naturais excepcionais, de beleza, grandiosidade, raridade, e para proteger exemplares raros da flora e da fauna oriundos dos estudos de instituições públicas e privadas no país (Drummond, 2010).

O crescente processo de degradação dos ambientes naturais gerou iniciativas em escala mundial para criação de áreas legalmente protegidas, por legislação específica e com regime de uso voltado à conservação. No passado, a escolha de uma área protegida se dava com base no uso dos recursos naturais, depois para preservar aspectos cênicos, potencialidades de lazer e na disponibilidade de terra. Várias unidades de conservação no mundo foram criadas a partir desta perspectiva. Com o avanço do conhecimento sobre a diversidade biológica e com a fundamentação teórica da biologia da conservação, novos critérios são considerados relevantes, que mais tarde gera uma nova forma de pensar as UCs (Vitali \& Uhlig, 2010).

Na política nacional de conservação da natureza, até o início do século XX temos uma posição utilitarista, que não se preocupava com a conservação da natureza para as futuras gerações, e sim para uso econômico. O regime republicano instalado no Brasil não tinha interesse em criar políticas para poupar o que restava de natureza. Até 1910, São Paulo, Minas Gerais e Paraná possuíam códigos florestais estaduais, mesmo que pouco aplicados. A fase das Guerras Mundiais refletiu no país com a falta de lenha e de demais recursos naturais necessários para mover a indústria e vida social (Dean, 1996). A partir da escassez de recursos para avançar o desenvolvimento se acentua a preocupação sobre a natureza, mesmo ainda de cunho utilitarista. O pensamento ambiental internacional influenciou no país o surgimento de instituições para regular a natureza, como o Serviço Florestal Brasileiro nos anos 1920, e posteriormente o Instituto Brasileiro de Desenvolvimento Florestal em 1967 (Vianna, 2008).

A partir da década de 1930 o governo federal convocou os estados para doarem terras para a criação de reservas. No nacionalismo no governo varguista, os recursos naturais passaram a ser vistos como uma reserva coletiva a ser usada eficientemente em favor da nação, mesmo sem muita adesão. É a partir de Vargas que temos a organização de políticas para gerenciar os recursos 
naturais, e forte preocupação com a criação de parques. Nesse contexto cientistas vincularam seus discursos às ideias do Estado para inserir o pensamento conservacionista, sendo um dos mais importantes o botânico Alberto José de Sampaio, diretor do Museu Nacional, que escrevia a favor do reflorestamento e das reservas naturais desde 1912 (Dean, 1996).

Em 1926, Sampaio retornando da Conferência de Roma apresenta um relatório que atribui ao governo e ao Serviço Nacional de Florestas a criação de guardas-florestais, e caberia ao estado intervir nas áreas privadas que são desmatadas. Além disso, nesse momento a sociedade civil através de associações e clubes com objetivos conservacionistas motivam a formação de um rol de políticas de teor conservacionistas desenvolvidas principalmente a partir da Era Vargas. Nesse processo, foi organizada a primeira Conferência Brasileira de Conservação da Natureza em 1934, com o objetivo central de pressionar o governo para implementar políticas para criar um sistema de parques de conservação para frear a exploração pautada no crescimento econômico nas áreas públicas e privadas (Dean, 1996).

Até a década de 1930, o debate conservacionista na política pairava em observações impressionistas, vencidas pelos desenvolvimentistas e suas ações e ideias alteravam a condição da natureza e eram apoiadas pela população. Conforme afirmou Dean (1996), a maioria dos habitantes do bioma Mata Atlântica viviam da extração de recursos da floresta, sendo a lenha usada na cozinha, na pequena e grande indústria, no comércio e por todas as classes sociais. As siderúrgicas e as hidroelétricas, e a produção de bens pelas indústrias ampliaram os avanços da devastação da floresta. Ao mesmo tempo, se criava um imaginário que a floresta era insalubre e era responsável pelas principais epidemias e doenças do contexto. A primeira e segunda década do século XX foram marcadas pela exploração do café, e avanço da malha ferroviária e exploração da madeira, principalmente como combustível. A partir dos anos 1930 o algodão passa a fazer parte do cenário da ocupação de áreas florestais, assim como as monoculturas de cana, aipim, milho e fumo. Nesse contexto as empresas ferroviárias passaram a criar parques de reflorestamento, principalmente com eucaliptos para alimentar as caldeiras, o que motiva outros setores industriais e sociedades. Da mesma forma o pequeno produtor é incentivado a substituir a mata nativa para o plantio do eucalipto com a promessa de mercado para a indústria (Dean, 1996).

Os discursos dos cientistas vinculados ao desenvolvimento do Estado varguista motivaram o governo a decretar uma série de medidas conservacionistas, como códigos regulamentando expedições científicas, uso da água, mineração, caça, pesca, e de controle florestal. A Constituição de 1934 encarregou os estados e governo central a regular a exploração dos recursos naturais e belezas naturais do país. O Código Florestal de 1934 proíbe o corte de árvores em áreas privadas da mata ciliar e em mananciais de água, e de espécies raras, obrigando a conservação de trechos dos lotes na área rural, e indústrias precisam replantar árvores conforme a exploração. Esboçavase a criação de uma guarda-florestal, que origina em seguida a Polícia Militar Ambiental, assim como traça regras sobre áreas de conservação e preservação. Da mesma forma, os estados e municípios instalaram conselhos florestais em conformidade com o Código Florestal e criaram parques, e nos municípios surgiram estâncias (Dean, 1996). O Código Florestal regimentou as categorias possíveis de parques, classificando quatro tipos: parques de florestas protetoras, remanescentes, modelos e produtivas. As primeiras são áreas conservadas e entendidas como 
parques nacionais, estaduais e municipais que surgiram a partir da década de 1930, tendo como marco a criação do Parque Nacional do Itatiaia em 1937, e depois o de Iguaçu e Serra dos Órgãos em 1939 (Drummond, 2010).

Após o governo Vargas não houve mudanças significativas nas políticas desenvolvidas, ao contrário do que ocorria na política internacional. Até 1930, conforme Vianna (2008) se estabeleceram parques nacionais em várias partes do mundo, mas não existia um consenso para designar essas áreas. Firmaram-se uma série de acordos internacionais, como o de Londres em 1933, chamado de Convenção para a Preservação da Fauna e Flora em seu estado natural. Depois disso ocorreram as Convenções de Washington em 1940, e da Venezuela em 1941. Em 1948 a UNESCO funda a União Internacional de Proteção da Natureza (IUPN) englobando agências governamentais e não governamentais. Em 1960 a IUPN cria a Comissão de Parques Nacional e Áreas Protegidas (CPNAP), passando a monitorar mundialmente a criação e gestão dos parques de conservação.

Em 1962, na cidade de Seattle (EUA), foi realizada a primeira Conferência Mundial sobre Parques Nacionais. Em 1972 a Conferência de Estocolmo representou um momento de clivagem na política ambiental mundial, e que reflete diretamente na política brasileira. Em Estocolmo é a primeira vez que uma discussão engloba muitas nações e setores sociais, que favorece o estabelecimento de uma agenda política mundial refletindo na política da União Internacional de Conservação da Natureza (IUCN), antiga IUPN, em discutir e normatizar o que tinha sido apontado por diversos movimentos sociais sobre o fator humano no interior de áreas protegidas. A conferência definiu que os povos tradicionais fazem parte da biodiversidade e dos sistemas naturais dos parques, que enriquecem as discussões de zoneamento dos parques. A consequência global é a criação de uma nova categoria, e formula-se o conceito de Reserva da Biosfera, tendo como relevância o entendimento da presença humana na conservação dos ambientes (Vianna, 2008).

Um dos resultados da Conferência de Estocolmo na política brasileira foi o arranjo estatal que originou a Secretaria Especial do Meio Ambiente (SEMA), passo conclusivo na política de criação de áreas de conservação. Assim, além do Instituto Brasileiro de Desenvolvimento Florestal (IBDF), com a nova secretaria no país dois órgãos distintos começaram a gerenciar parques. $O$ IBDF, em 1979, organiza o I Plano do Sistema Nacional de Unidades de Conservação do Brasil, e nesta ocasião criaram-se critérios técnico-científicos para a seleção de áreas para parques nacionais, e reservas biológicas, assim como ficou prevista categorias de unidades de conservação para proteger monumentos naturais, santuários da vida silvestre, rio cênico, estrada parque, reserva de recursos, reserva de fauna, parque natural e monumento cultural. Entretanto, nem todas essas categorias foram confirmadas em legislações posteriores (Vianna, 2008).

A partir de 1980 no Brasil inicia uma fase de elaboração de planos de manejo dos parques já criados, demonstrando o interesse em ordenar a gestão dessas áreas no país. Nesse sentido, a SEMA criou novas categorias de unidades, como as Estações Ecológicas e Áreas de Proteção Ambiental. A criação desta última categoria, APA, promoveu no país uma modalidade de unidade com a inserção da sociedade humana na área. E como maior resultado do processo após Estocolmo, já em 1982 é organizada a II Etapa do Plano do Sistema de Unidades de Conservação, e com isso se desenvolveu a Política Nacional de Meio Ambiente (PNMA) e a utilização do conceito 
de desenvolvimento sustentável difundido na conferência mundial do meio ambiente (Vianna, 2008).

Através da PNMA a questão da conservação de áreas no país se amplia no cenário político, principalmente com a criação do Ministério do Desenvolvimento Urbano e Meio Ambiente em 1985, que assume as questões ambientais no país. Uma das principais ações foi a delimitação de novas áreas para criação de parques, desencadeando o surgimento do Sistema Nacional de Meio Ambiente (SISNAMA) que cuida da gestão das áreas conservadas. No sistema é estabelecido como órgão máximo o Conselho Nacional do Meio Ambiente (CONAMA) (Vianna, 2008).

A política de criação de unidades de conservação ou de áreas de proteção ambiental coincidiu com o chamado período da democratização nacional, entre 1984 e 1990, quando os problemas ambientais brasileiros começaram a merecer maior atenção, pois a degradação atingia os remanescentes florestais, tanto por parte da sociedade como do governo. A política de Unidades de Conservação no Brasil concebe que a conservação ambiental deve ter como uma de suas metas de preservar espaços isolados da convivência humana, para que a natureza possa sobreviver aos impactos das transformações (Vianna, 2008). Quase todas as análises políticas sobre a criação e a implantação das Unidades de Conservação se restringem ao que foi decidido pelo governo. Muito pouco se tem registrado sobre o processo que movimenta os diferentes setores que atuam nessa questão. É preciso um esforço de análise para compreender as ações do poder público, das organizações não governamentais e dos moradores locais, para que se possa interpretar corretamente o estado real dessa política pública, o que reflete na necessidade de estudos que aprofundem a história (Furlan \& Nucci, 1999).

De acordo com Lenzi (2005), as políticas ambientais decorrentes dos anos 1980-90 fazem parte de um período denominado de Modernização Ecológica. É um momento onde o movimento ambientalista parte dialogando com o capital e conquista espaço na agenda política. Os temas ambientais se incorporam nas campanhas, dando à ciência e à tecnologia espaço para apontar soluções. Nas discussões científicas, as áreas de conservação e corredores ecológicos constituem uma das principais estratégias nesse período. Vianna (2008) afirma que o final do século XX fica marcado por possuir inúmeras políticas com foco na conservação da natureza, prezando a qualidade ambiental, e tendo como principal ação a criação de parques. Uma das principais marcas nesse avanço foi a Constituição de 1988, tendo o meio ambiente como um direito fundamental do povo brasileiro e obrigação do Estado prover. No mesmo ano, também há uma reformulação do Plano de Sistemas de Unidades de Conservação elaborado anteriormente pelo IBDF, e neste contexto novas categorias aparecem como as Reservas Extrativistas. Em 1990 o CONAMA determina a área mínima de entorno das UCs para $10 \mathrm{~km}^{2}$, e neste perímetro o uso se dá por licenciamentos especializados. Vale ressaltar que em 1989 o IBDF e a SEMA são fundidos e é criado o Instituto Brasileiro de Meio Ambiente e dos Recursos Renováveis (IBAMA), e nos anos 1990 é criado o Ministério do Meio Ambiente ficando o IBAMA subordinado a ele.

Em 1992 é realizada no Rio de Janeiro a Conferência das Nações Unidas para o Meio Ambiente, onde diversos chefes de estado debateram a sustentabilidade do desenvolvimento, tendo como resultado a assinatura de diversos tratados e planos de ações, entre eles a Convenção da Diversidade Biológica. Segundo Vianna (2008), a partir disso a criação de parques no país muda seu caráter utilitarista e de preservação de cenários, e a política ambiental brasileira passa a 
incorporar o tema da conservação da biodiversidade. Os três principais aspectos da convenção foram: a conservação da biodiversidade, proteção dos ecossistemas através de áreas protegidas e proteção das comunidades e conhecimentos tradicionais do povo brasileiro (Vianna, 2008).

Após a Convenção da Diversidade Biológica da Rio 92, intensificaram-se os esforços políticos para a criação de Unidades de Conservação. A partir do dia 18 de julho de 2000 a conservação da natureza no Brasil tem um novo e importante referencial: a Lei n.9985, sancionada pelo vice-presidente da República instituindo o Sistema Nacional de Unidades de Conservação da Natureza, mais conhecida como Lei do SNUC. A lei em seu capítulo III dispõe sobre as Categorias de Unidades de Conservação, onde as divide em: I - Unidades de Proteção Integral e II - Unidades de Uso Sustentável. Entendem-se como unidades de conservação todas as áreas protegidas que possuem regras próprias de uso e de manejo, com a finalidade própria de preservação e proteção de espécies vegetais ou animais, de tradições culturais, de belezas paisagísticas, ou de fontes científicas, dependendo da categoria em que se enquadra (Schenini, Costa \& Casarin, 2004). As unidades de conservação são organizadas em categorias, definidas como categorias de manejo, cada qual atendendo prioritariamente a determinados objetivos, que poderão ter maior ou menor significado para a preservação dos ecossistemas naturais.

Schenini, Costa \& Casarin (2004) afirmaram que após mais de 8 anos de estudos, o SNUC vem a auxiliar o ordenamento das inúmeras leis dispostas sobre as diversas categorias de manejo, como também vem a definir critérios e normas para o estabelecimento e gestão das áreas protegidas, sejam estas federais, estaduais ou municipais. Fica estabelecido que no ato de criação de uma UC sejam realizadas consultas públicas para analisar a melhor das categorias, exceto para Estações Ecológicas e Reservas Biológicas, assim como também se torna necessária a participação popular para ampliar e para mudar a categoria das UCs. Assim, as consultas públicas têm caráter "consultivo" e servem para que a população seja informada sobre os propósitos da criação das UCs e contribua com informações e sugestões.

De acordo com a Lei do SNUC, as Unidades de Proteção Integral têm como objetivo básico a preservação da natureza, sendo permitido apenas o uso indireto dos recursos da unidade. Nas Unidades de Uso Sustentável objetiva-se compatibilizar a conservação da natureza com o uso sustentável de parcela de seus recursos naturais (SNUC, 2000).

As Unidades de Conservação são criadas pelo poder público, que de acordo com o Capítulo IV da referida Lei são precedidas de estudos técnicos e de consulta pública para identificar localização, dimensões, e limites. Nas consultas públicas são informadas as populações locais e partes interessadas. Esta fase de estudos fornece subsídios para determinação do tipo de UC, e se a área é indicada para Uso Sustentável ou Proteção Integral, isto baseado nas características da área (SNUC, 2000).

\subsection{A criação de áreas protegidas no Vale do Itajaí}

O processo histórico de criação de UCs em Santa Catarina e no Vale do Itajaí estava atrelado aos acontecimentos das políticas nacionais e influências externas de movimentos ambientalistas. Assim como no restante do país, diversos grupos externos com interesses econômicos na exploração da natureza tiveram como plano de fundo as atitudes de conservação 
nas políticas do Estado. Na história da ocupação e colonização do território, principalmente a partir do século XIX, diversos grupos econômicos iniciaram o processo com a preocupação de instalação de núcleos para dispersar o modelo exploratório do capital sobre o ambiente. Além disso, conforme Borinelli (2013), o empreendedorismo e a disciplina do trabalho com a fartura dos recursos naturais foram imprescindíveis para a constituição das bases do modelo de desenvolvimento catarinense.

Durante as primeiras décadas do século XX a política do estado catarinense não conseguiu frear a exploração dos recursos naturais havendo desde a guerra do Contestado, o período do ciclo da madeira, a questão indígena, e políticas que não conservaram a Mata Atlântica remanescente da espoliação colonial. Conforme Lenzi (2005), o período republicano ficou atrelado a três famílias perdurando até o cenário atual, e nem o código Florestal de 1934, nem as atividades do Serviço Florestal e mais tarde do Instituto Brasileiro de Desenvolvimento Florestal caminharam no sentido da conservação, apenas da preocupação do uso utilitarista. Ao chegar em 1960-70 as atividades extrativistas e industriais instaladas no estado promoveram rápido crescimento econômico e ao mesmo tempo de intensa exploração. Nos anos 1970 o modelo catarinense de desenvolvimento demonstrava como as suas intenções não se preocupavam com o ambiente. Diversos movimentos sociais surgiram em defesa do que havia sobrado das florestas (Borinelli, 2013).

De acordo com Lenzi (2005), em Santa Catarina as políticas de conservação ocorrem no período denominado na Sociologia Ambiental de Modernização Ecológica, ou seja, a partir dos anos 1960-70, com o acúmulo dos problemas ambientais, as manifestações sociais, e a influência das políticas ambientais internacionais na instituição de novas normativas de interesse no poder político do Estado. As questões ambientais passaram a ter motivações, e elas decorreram assim como no processo da política nacional, a de criar áreas para evitar a exploração ou preservar recursos econômicos, fase que caminha até a ECO 92 quando a preocupação também é abarcar além das questões econômicas, a conservação da biodiversidade, como preconiza a Convenção da Diversidade Biológica. Vitali \& Uhlig (2010) apontam como reflexo dessa mudança a quantidade de parques que são criados no Estado, como o Parque Estadual do Tabuleiro em 1975, e em 1977 a Reserva Biológica do Sassafrás e o Parque Estadual da Serra Furada.

A partir de 1970, Santa Catarina, inserida na agenda política ambiental nacionalista dos militares, cria organismos com o intuito de gerenciar os recursos naturais. Em 1975 foi criada a Secretaria de Tecnologia e Meio Ambiente (SETMA), estando vinculada a ela a Fundação de Amparo a Tecnologia e Meio Ambiente (FATMA), organismos que atuaram mais no setor econômico que conservacionista, mas garantiu uma série de medidas que diminuíram e regularam os processos exploratórios (Lenzi, 2005). O primeiro secretário nomeado na FATMA foi o senhor Augusto Batista Pereira, empresário do setor carbonífero, que impôs um ritmo de influência econômica nas políticas ambientais, mas ao seu lado, em benefício da conservação estava o botânico Padre Raulino Reitz. Conforme Borinelli (2013), o botânico é um dos principais responsáveis pelas políticas de criação de parques estaduais, cuja influência se estende até o final do século $X X$.

No Vale do Itajaí, Santa Catarina, a cultura de conservação utilitarista sempre esteve presente no modelo colonizador implantado na região. Pela foz do rio Itajaí, a colonização se deu 
por portugueses, açorianos, madeirenses e vicentinos. Subindo o rio Itajaí-açú diversas incursões de mineradores e exploradores de madeira estiveram na região entre o século XVI e XVIII. A partir do século XIX ocorre a colonização de alemães, poloneses, italianos, e ucranianos, além das migrações internas que se fixaram no vale no percurso entre o Rio Grande do Sul e São Paulo. No início do processo de ocupação e colonização predomina a alemã e italiana (1830-70), e neste período se estima, segundo Bacca (2008), aproximadamente 700 moradores na região, caboclos ou luso-brasileiros, e milhares de indígenas, vivendo e caçando nas matas. Com a chegada dos novos colonos do mundo industrializado europeu, a natureza do vale passa a transformar-se rapidamente. A venda dos lotes por Dr. Blumenau (fundador da colônia Blumenau em 1850) inicia um processo de derrubada da floresta para a obtenção de lenha e madeira, assim como para o estabelecimento das lavouras, pastagens, edificações, estradas e demais feitos são responsáveis no vale por um "[...] admirável progresso humano, que passou a avançar num ritmo inversamente à inevitável supressão, alteração e poluição do ambiente natural [...]" (Bacca, 2008, p. 23). Uma das principais medidas da época da colônia foi o Código de Posturas, ordenando as práticas de uso dos recursos ambientais e organização do espaço público e de floresta (DAY, 2015). Estudos de Lenzi (2006) e Bacca (2008) apontam que foi a aspiração do imigrante um dos principais fatores para o pioneirismo da conservação ambiental, que da colônia Blumenau se difunde por todo o vale.

Conforme Bacca (2008), Dr. Blumenau trouxe à região a preocupação com a criação de jardins, sendo uma prática constatada também nos outros alemães que na região viriam a se fixar. Em simetria com outras regiões do país, o Vale do Itajaí recebia cientistas e viajantes, com objetivos de produzir conhecimento sobre a floresta da região. Um dos mais relevantes foi Fritz Muller. O cientista desenvolveu diversos estudos na região e atuou como professor incentivando gerações a ter curiosidade pela natureza e pensar na sua conservação. Como já mencionado, junto a outros cientistas, Fritz se correspondia com Landislau de Souza Mello Neto, coordenador do Museu Nacional no Rio de Janeiro, assim como Charles Darwin e outros (Dean, 1996).

Bacca (2008) afirma que nessa mesma época, August Muller, irmão de Fritz Muller, com formação científica pelo Jardim Botânico de Berlim dedicou-se à jardinagem na colônia Blumenau. Assim como Guilherme Friedenreich, amigo dos Muller se dedicou a colecionar insetos, e depois foi trabalhar no Museu Paulista onde está sua coleção.

Os primeiros imigrantes, conforme Bacca (2008), que chegaram com Dr. Blumenau trouxeram a cultura da conservação. Alguns exemplos de pioneirismo fundamentam a ação política da região sobre a conservação e criação de áreas protegidas, pessoas que se destacaram durante a formação do município de Blumenau - até o Estado Novo, o território de Blumenau equivalia em grande parte ao Vale do Itajaí $\left(15.500 \mathrm{~km}^{2}\right)$ - e em sua história por deixar contribuições para o pensamento ambiental local-global. Em 1898, o prefeito do município de Blumenau, José Bonifácio Cunha, apresentou um plano de aquisição de terras nas cabeceiras dos mananciais em torno de Blumenau, tendo o objetivo de usar as águas para distribuir na cidade com uma rede de encanamento. $E$ algumas áreas de propriedades de indústrias que se instalaram na região no final do século XIX são protegidas. A área criada por Max Vitor Hering, por exemplo, configura a Reserva Florestal da Cia Hering, no Vale do Bom Retiro, região central de Blumenau. $O$ objetivo era conservar a floresta e os mananciais para a utilização na indústria têxtil. 
No século XX, o botânico João Geraldo Kuhlmann realizou diversos estudos de árvores e palmeiras plantadas por Dr. Blumenau, e da região. Também produziu mais de sessenta estudos de botânica sistêmica, descrevendo três novas famílias, sete novos gêneros e oitenta e quatro espécies. Foi um dos fundadores da Sociedade Botânica do Brasil, e retirando-se de Blumenau assume a direção do Jardim Botânico do Rio de Janeiro. Atuavam, ainda na sociedade, pessoas que influenciaram as novas gerações nascidas e que passaram a ter Blumenau e região o seu ambiente/habitat. Como o professor Rudolf Hollenweger, que estimulava seus alunos no início do século XX a conhecer a floresta e defendia a preservação de áreas, assim como inaugurou a atividade do excursionismo no município. É um dos fundadores do Spitzkopf Clube, instituição com objetivos conservacionistas com atividades contra a caça predatória e extinção de espécies da região. O professor Max Humpl deixou um diário com apontamentos sobre os problemas da exploração e da necessidade da conservação (Bacca, 2008).

Na região, na década de 1960, a criação de uma faculdade em Blumenau, atual Fundação Universidade Regional de Blumenau (FURB), contribui para influenciar a sociedade do Vale do Itajaí. O primeiro curso de História Natural do estado foi criado na FURB em 1969, com respaldo técnico-científico para o movimento ambiental que aflorava na região. Como professores do curso, os padres e botânicos Raulino Reitz e Roberto Miguel Klein tiveram um papel importante para influenciar o movimento ambiental regional e as políticas de conservação local e regional/estadual. Estes padres durante os anos 1950-70 realizaram diversos estudos científicos sobre a fauna e flora local, sendo responsáveis por estudos da malária, assim como participaram na política ambiental local, e no estado pela FATMA (Bacca, 2008).

Os anos 1970 também representaram, como em outras regiões do estado e do país, um momento de aceleração do crescimento econômico. A floresta que cobre os municípios do Vale do Itajaí sofre com os efeitos do desenvolvimento. Cada vez mais se sente os impactos causados pela poluição hídrica, atmosférica e sonora. O crescente aumento da degradação ambiental e da influência da mídia externa e dos movimentos ambientais condiciona a região a incorporar medidas pensadas a partir do relatório do Clube de Roma, da Conferência Mundial sobre o Meio Ambiente em Estocolmo e de organizações que defendiam a ideia de criação de áreas protegidas. O pioneirismo na região, e a influência das discussões internacionais, nacionais e locais sobre a problemática ambiental estimulam a criação de ONGs, como a Associação Catarinense de Preservação da Natureza (ACAPRENA), e no âmbito governamental secretarias especializadas, como a Assessoria Especial do Meio Ambiente (AEMA) em 1977, ambas no município de Blumenau (Bacca, 2008).

De acordo com a ACAPRENA (2015), a ONG foi criada em maio de 1973 pela iniciativa de um grupo de estudantes do curso de Ciências Biológicas da FURB (antes História Natural), com o nome de Associação Catarinense de Defesa da Flora e da Fauna (ACDFF). Esses estudantes mantinham correspondência com membros de outras ONGs que surgiram no país, como a Associação Gaúcha de Proteção dos Ambientes Naturais (AGAPAN), do Rio Grande do Sul e, a Associação de Defesa da Flora e da Fauna, de São Paulo. A ACAPRENA é a primeira associação ambiental catarinense, e terceira nacional. Entre suas principais conquistas foi a influência para a criação da Secretaria de Tecnologia e Meio Ambiente (SETMA), e da Fundação de Amparo à Tecnologia e Meio Ambiente (FATMA), no governo estadual, e no Vale do Itajaí, principalmente 
em Blumenau, fomentou a criação da Assessoria Especial do Meio Ambiente, gestão do prefeito Renato de Mello Vianna.

A ACAPRENA no Vale do Itajaí representou uma difusora das ideias de conservação, na criação de UCs, e estimula o surgimento de outras ONGs que tiveram importante papel na região, como a Associação de Preservação do Meio Ambiente e da Vida (APREMAVI). Esta ONG foi fundada em julho de 1987 em Ibirama (APREMAVI, 2015), e passou a atuar no Alto Vale do Itajaí na repressão da devastação florestal, assessorando o desenvolvimento de propriedades privadas sustentáveis, e estimulando o reflorestamento com espécies nativas da Mata Atlântica. No Alto Vale do Itajaí também se insere na articulação de políticas ambientais de criação de UCs.

Portanto, na história de criação de áreas protegidas no Vale do Itajaí há diversas motivações que vão desde a influência do movimento ambiental internacional, de um pioneirismo de conservação trazido pelos imigrantes que aqui se fixam com a presença de importantes cientistas, assim como questões locais, particularidades e grupos de pessoas envolvidos. Posteriormente dos eventos organizados pelas Nações Unidas e de suas políticas desenvolvidas, assim como das reformas constitucionais e das ações dos organismos federais, estaduais e municipais em simetria com a pressão do movimento ambientalista local contrário ao modelo de desenvolvimento pautado na exploração intensa da natureza; aliada à ideia de criar áreas para conservar recursos, belezas e a biodiversidade para as futuras gerações. Conforme Lenzi (2006), a região desde o início de sua colonização possui uma vocação para a conservação, e isso influenciou a formação de uma agenda de políticas que ressoaram no Vale do Itajaí no momento presente a uma modernização ecológica.

O levantamento de Unidades de Conservação possibilitou verificar que além das motivações já ressaltadas, um momento na política nacional/estadual está atrelado a uma particularidade local, pois cada UC tem uma história própria para a escolha da categoria. E foram as características ambientais e a influência da sociedade local que determinaram a política de criação de UCS federais, estaduais e municipais na região. Nos levantamentos realizados para listar as UCs no Vale do Itajaí, identificaram-se 42 áreas dedicadas à conservação, destas 27 enquadradas no SNUC.

Tabela 1 - Unidades de Conservação do Vale do Itajaí (Federal, Estadual e Municipal).

\begin{tabular}{|c|c|c|c|c|}
\hline Unidade de Conservação & Localidade & Categoria & Esfera & $\begin{array}{l}\text { Ano de } \\
\text { criação }\end{array}$ \\
\hline FLONA de Ibirama & Ibirama & Uso Sustentável & Federal & 1965 \\
\hline REBIO do Sassafrás & $\begin{array}{c}\text { Doutor Pedrinho e } \\
\text { Benedito Novo }\end{array}$ & Proteção Integral & Estadual & 1977 \\
\hline & Botuverá e Nova & & & \\
\hline REBIO da Canela Preta & Trento & Proteção Integral & Estadual & 1980 \\
\hline Parque Municipal da Ressacada & Itajaí & Uso Sustentável & Municipal & 1982 \\
\hline ARIE da Serra da Abelha/Rio da Prata & Vitor Meirelles & Uso Sustentável & Federal & 1990 \\
\hline ARIE Roberto Miguel Klein & Blumenau & Uso Sustentável & Municipal & 1992 \\
\hline Parque Natural Municipal São & & & & \\
\hline Francisco de Assis & Blumenau & Proteção Integral & Municipal & 1995 \\
\hline
\end{tabular}




\begin{tabular}{|c|c|c|c|c|}
\hline APA São Francisco de Assis & Blumenau & Uso Sustentável & Municipal & 1995 \\
\hline ARIE Foz do Ribeirão Garcia & Blumenau & Uso Sustentável & Municipal & 1995 \\
\hline $\begin{array}{l}\text { Parque Natural Municipal Nascentes } \\
\text { do Garcia }\end{array}$ & Blumenau & Proteção Integral & Municipal & 1998 \\
\hline APA Ilhas Fluviais Rio Itajaí-Açú & Blumenau & Uso Sustentável & Municipal & 1999 \\
\hline $\begin{array}{l}\text { Parque Natural Municipal Grutas de } \\
\text { Botuverá }\end{array}$ & Botuverá & Proteção Integral & Municipal & 1999 \\
\hline APA do Bateias & Gaspar & Uso Sustentável & Municipal & 2000 \\
\hline APA Padre Raulino Reitz & Blumenau & Uso Sustentável & Municipal & 2001 \\
\hline Parque Natural Municipal Bromberg & Blumenau & Proteção Integral & Municipal & 2002 \\
\hline APA do Brilhante & Itajaí & Uso Sustentável & Municipal & 2003 \\
\hline PARNA da Serra do Itajaí & $\begin{array}{l}\text { Vale do Itajaí } \\
\text { (9 municípios) }\end{array}$ & Proteção Integral & Federal & 2004 \\
\hline $\begin{array}{l}\text { Parque Natural Municipal Ilha das } \\
\text { Capivaras }\end{array}$ & Itajaí & Proteção Integral & Municipal & 2006 \\
\hline Parque Natural Municipal da Atalaia & Itajaí & Proteção Integral & Municipal & 2007 \\
\hline Parque Natural Municipal Cordeiros & Itajaí & Proteção Integral & Municipal & 2007 \\
\hline ARIE do Salto & Blumenau & Uso Sustentável & Municipal & 2007 \\
\hline APA Saco da Fazenda & Itajaí & Uso Sustentável & Municipal & 2008 \\
\hline $\begin{array}{l}\text { Parque Natural Municipal Chapéu das } \\
\text { Águas }\end{array}$ & Vidal Ramos & Proteção Integral & Municipal & 2010 \\
\hline $\begin{array}{l}\text { Parque Natural Municipal Freymund } \\
\text { Germer }\end{array}$ & Timbó & Proteção Integral & Municipal & 2011 \\
\hline $\begin{array}{l}\text { Parque Natural Municipal de } \\
\text { Navegantes }\end{array}$ & Navegantes & Proteção Integral & Municipal & 2011 \\
\hline $\begin{array}{l}\text { Refúgio de Vida Silvestre Raulinoa } \\
\text { echinata }\end{array}$ & Lontras e Apiúna & Proteção Integral & Estadual & 2015 \\
\hline APA do Rio Itajaí Mirim & Botuverá & Uso Sustentável & Municipal & $\begin{array}{c}\text { Não } \\
\text { encontrado }\end{array}$ \\
\hline
\end{tabular}

Fonte: Elaboração própria.

As 27 Unidades de Conservação do Vale do Itajaí (Tabela 1) distribuem-se nas duas categorias, de proteção integral e de uso sustentável, sendo 3 na esfera federal, 3 estaduais e 21 municipais. Dentre as UCs federais uma está classificada como Parque Nacional, enquadrada na categoria de Proteção Integral, o Parque Nacional Serra do Itajaí, maior UC do vale com 57.374 hectares. Também são federais a Floresta Nacional de Ibirama e a Área de Relevante Interesse Ecológico Serra da Abelha, ambas enquadradas como de Uso Sustentável. O enquadramento mais frequente de UC é a de parque (12 UCs).

No Vale do Itajaí as 3 UCs estaduais, todas de proteção integral, estão representadas pelas Reservas Biológicas da Canela Preta e do Sassafrás, e pelo Refúgio da Vida Silvestre Raulinoa echinata, está em processo de implantação.

As 21 UCs municipais estão distribuídas em sete municípios, sendo 9 em Blumenau, e 6 em Itajaí. Dentre as UCs municipais, 14 se enquadram na categoria de Proteção Integral, representadas por 11 Parques Naturais Municipais e 3 Áreas de Relevante Interesse Ecológico. Na categoria de Uso Sustentável estão classificadas 7 Áreas de Preservação Ambiental. No Vale do 
Itajaí, o município de Blumenau apresenta o maior número de UCs (10), sendo que o Parque Nacional da Serra do Itajaí abrange o seu território em 9 municípios.

Dentre as 27 UCs (Figura 2) pesquisadas no Vale do Itajaí 5 antecedem a ECO 92, que foram criadas com objetivos específicos por questões locais. No caso das REBIO da Canela Preta (1980) e do Sassafrás (1977), conforme decretos, as UCs foram criadas para proteger espécies exploradas e ameaçadas de extinção na época de sua criação. A FLONA de Ibirama foi criada para a produção e distribuição de mudas nativas e exóticas para reposição das florestas extremamente exploradas no Vale do Itajaí no período que a antecede. A ARIE Roberto Miguel Klein (1992), criada em função da construção de uma obra pública, mantém um trecho da área afetada. No caso da ARIE Serra da Abelha (1990), o objetivo é manter os ecossistemas em seu estado natural, e regular o uso admissível dessas áreas, de modo a compatibilizá-lo com os objetivos de conservação da natureza (OBSERVATÓRIO DAS UCs, 2015). A grande maioria das UCs do Vale do Itajaí (22) foram criadas após a ECO 92, convergindo com as políticas nacionais de conservação.

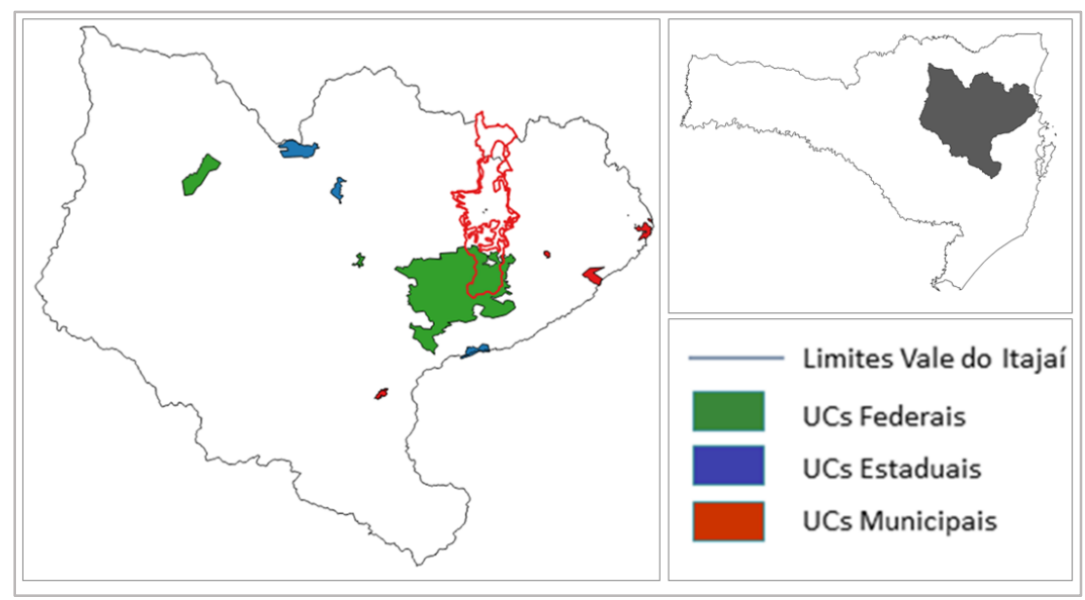

Figura 2: Unidades de Conservação no Vale do Itajaí. Fonte: Elaboração própria.

A influência pública em criar áreas de preservação ou conservação no Vale do Itajaí tornase presente a partir dos anos 1950-60, e efetivando a criação de diversas unidades a partir de 1970. Em 1950 o Horto Florestal de Ibirama, também conhecido como Posto de Fomento Florestal de Ibirama era administrado pelo Instituto Nacional do Pinho (INP) e o Estado de Santa Catarina, passando a ser gerida pelo IBDF em 1967. Entre as atividades desenvolvidas naquele período, está a produção e venda de mudas de espécies florestais nativas e exóticas, entre elas a canela sassafrás, da qual uma usinava operava na obtenção do óleo safrol, além da exploração de canelas pretas, cedros, perobas e muitas outras que tinham valor comercial. Também eram produzidas mudas no horto para a realização de plantios na própria unidade, como Araucária (1950-1960), Pinus (1970-1975) e Eucalipto (em data indefinida), assim como teve o papel de difundir as espécies na região. Após a implementação dos plantios, essas áreas não sofreram nenhum tipo de manejo ou trato cultural, por consequência, resultaram em reflorestamentos de baixa qualidade e valor comercial. O Decreto Federal n 95.818, de 11 de março de 1988, dá uma nova destinação à área com a denominação de Floresta Nacional de Ibirama (OBSERVATÓRIO DAS UCs, 2015). 
A FLONA de Ibirama possui diversas espécies de fauna e flora endêmicas, sendo alguns presentes nas listas de extinção, assim como é habitat de espécies que foram intensamente exploradas no passado, o que garante níveis significativos de biodiversidade. A região do entorno possui uma forte capacidade para o ecoturismo e atividades sustentáveis (OBSERVATÓRIO DAS UCs, 2015).

A primeira intenção oficial do Estado de Santa Catarina em criar uma área de conservação no Vale do Itajaí é com a REBIO Sassafrás, criada em 4 de fevereiro de 1977, por meio do decreto número 2.221, e é dividida em duas áreas: uma com 3.862 hectares no município de Doutor Pedrinho, e outra com 1.361 hectares no município de Benedito Novo. Abrigando uma área remanescente da Floresta Atlântica, a reserva ganhou esse nome por ser o habitat da Canela Sassafrás, uma espécie de árvore que se encontra ameaçada de extinção. A porção que corresponde à maior área da REBIO é a que permanece mais bem preservada. Um dos fatores de sua grande exploração deve-se à produção do óleo safrol que se destinava à exportação. A sua criação como unidade de conservação está associada ao interesse do estado em manter reservas e como forma de pagamento de dívidas por parte de uma empresa que repassa as terras ao governo, cabendo à FATMA a sua administração.

A REBIO Sassafrás possui uma gleba com altíssimo nível de biodiversidade, e com presença de espécies de árvores que historicamente sofreram alta exploração. Possui flora e fauna endêmicas, e o entorno possui capacidade e qualidade para o desenvolvimento de atividades do turismo rural, e ecoturismo (OBSERVATÓRIO DAS UCs, 2015).

Posteriormente o governo cria a REBIO Canela-Preta, que se estende pelos municípios de Botuverá e Nova Trento. Foi criada pelo Decreto número 11.232 de 20 de junho de 1980, com área de 1.844 hectares. Em seguida, anexaram-se 55 hectares por meio do Decreto número 4.840, de 23 de setembro de 1994, totalizando 1.899 hectares. A unidade foi criada para preservar a canela preta (Ocotea catharinensis), que é uma espécie da flora brasileira característica do bioma Mata Atlântica e está ameaçada de extinção. A canela preta, conforme Reitz et al. (1978, apud VITALI e UHLIG, 2010), chega a representar até um terço do volume em madeira em matas primárias da Floresta Ombrófila Densa de Santa Catarina. Devido à qualidade de sua madeira e o amplo uso para que se presta, essa espécie foi severamente explorada no Estado. Na REBIO Estadual da Canela Preta ainda é predominante a ocorrência dessa espécie, assim como, grande quantidade de palmiteiros. O relevo da região é caracterizado por inúmeros morros e vales, por onde escoam grandes volumes de água que formam a bacia do rio Itajaí-açú e a do rio Tijucas. Conforme o Observatório de UCs (2015), na região há inúmeros problemas decorrentes de empreendimentos de energia elétrica com a instalação de pequenas centrais hidroelétricas.

A Área de Relevante Interesse Ecológico da Serra da Abelha está situada no município de Vitor Meirelles, com área aproximada de 4.261 hectares. A ARIE está com seu plano de manejo em elaboração pela APREMAVI possuindo assim, somente a RESOLUÇÃO CONAMA n 5, de 17 de outubro de 1990. A intenção na criação da UC é a de manter os ecossistemas naturais de importância regional ou local, e regular o uso admissível dessas áreas, de modo a compatibilizá-lo com os objetivos de conservação da natureza (OBSERVATÓRIO DAS UCs, 2015). 
O Parque Nacional da Serra do Itajaí, conforme Plano de Manejo foi criado pelo Governo Federal, Decreto $s / n^{\circ}$, publicado no Diário Oficial da União (DOU) em 04 de junho de 2004. Protegem 57 mil hectares de florestas, em sua grande maioria em avançado estágio de regeneração. Uma boa parcela de seu território é composta por florestas primárias. Segundo o decreto de criação, o Parque Nacional da Serra do Itajaí possui os objetivos de preservar amostra representativa do bioma Mata Atlântica, de preservar os ecossistemas ali existentes, possibilitando a realização de pesquisa científica e o desenvolvimento de atividades de educação e interpretação ambiental, de recreação em contato com a natureza e de turismo ecológico. Abrange os munícipios de Ascurra, Apiúna, Blumenau, Botuverá, Gaspar, Guabiruba, Indaial, Presidente Nereu e Vidal Ramos. O Plano de Manejo é resultado da iniciativa de uma equipe multidisciplinar da ACAPRENA.

O Refúgio de Vida Silvestre Raulinoa echinata localiza-se nos municípios de Lontras e Apiúna ao longo do Rio Itajaí-açú, e ainda não possui decreto de criação e o plano de manejo está sendo elaborado pela empresa Socioambiental (OBSERVATÓRIO DAS UCs, 2015). A criação desta UC deve-se à preservação da espécie endêmica Raulinoa echinata ameaçada pela Usina Hidrelétrica Salto Pilão.

\section{CONSIDERAÇÕES FINAIS}

A criação das UCs municipais está relacionada com o desenvolvimento das políticas de conservação no país, tendo como motivação as especificidades locais de conservação de recursos naturais, salvaguardar as belezas naturais, e ampliar a proteção de outras UCs, motivadas por movimentos sociais ou conjunturas políticas locais.

O Vale do Itajaí tem uma história de criação de parques públicos decorrentes das políticas nacionais a partir de 1930, mas foi em 1960-70 até a década de 1980, que surgiu uma motivação social e cultural de conservação oriunda dos movimentos sociais, mas ainda de inspiração utilitarista. O estado de Santa Catarina a partir dos anos 1970 com a criação de secretarias ambientais, como a FATMA, aumenta a quantidade de áreas protegidas, e simultaneamente, no mesmo contexto, municípios por iniciativas sociais locais, criam parques. A partir dos anos de 1980, o processo de democratização e a influência dos resultados das conferências sobre o meio ambiente e dos movimentos sociais locais, temos por parte do poder público, a criação de diferentes tipos de parques, que além da intenção utilitarista, há uma preocupação em salvaguardar os remanescentes, a paisagem cênica, fauna e flora, conforme a política desenvolvida a partir da influência do Yellowstone nos EUA. Os parques criados a partir da década de 1990 começam a ter em seus objetivos preocupações conservacionistas atreladas à política da Convenção da Diversidade Biológica da ECO 92.

\section{REFERÊNCIAS}

Associação Catarinense de Preservação da Natureza - ACAPRENA. (2015). Histórico. Recuperado em 12 de janeiro, 2015, em http://www.acaprena.org.br/hp/index.asp? p_codmnu=1.

Associação de Preservação do Meio Ambiente e da Vida - APREMAVI. (2015). Trajetória.

Recuperado em 12 de janeiro, 2015, em http://www.apremavi.org.br/institucional/trajetoria/. 
Bacca, L. E. (2008). Diagnóstico preliminar dos aspectos históricos do Parque Nacional Serra do Itajaí (PNSI). Recuperado em 14 de dezembro, 2014, em: http://www.acaprena.org.br/planodemanejo/result_hist.asp.

Borinelli, B. (2013). Acomodando Estranhos: Origem e Trajetória da Política Ambiental no Estado de Santa Catarina (1975-1991). Anais do Encontro Nacional da Associação de Pós-Graduação e Pesquisa em Administração, 37, Rio de Janeiro.

Day, A. (2015). Túneis de Blumenau. Recuperado em 13 de janeiro, 2015, em www.adalbertoday.blogspot.com.

Dean, W. (1996). A ferro e fogo: a história e a devastação da Mata Atlântica brasileira. São Paulo: Companhia das Letras.

Drummond, J. A., Franco, J. L. A. \& Oliveira D. (2010). Uma análise sobre a história e a situação das Unidades de Conservação no Brasil. In: Ganem, R. S. (Org.). Conservação da biodiversidade: legislação e políticas públicas. Brasília: Edições Câmara.

Furlan, S. A. \& Nucci, J. C. (1999). Política de conservação das florestais tropicais no Brasil. In: Furlan, S. A \& Scarlato, F. C. (Org.). A Conservação das Florestais Tropicais. São Paulo: Atual.

Lenzi, C. L. (2006). Modernização Ecológica e a política ambiental catarinense. Revista de Ciências Humanas, Florianópolis, n. 39, abr., p. 117-134.

Lenzi, C. L. (2005). Sociologia ambiental: risco e sustentabilidade na modernidade. Bauru: EDUSC, 2005.

Mazoyer, M. \& Roudart, L. (2010). História das agriculturas no mundo: do neolítico à crise contemporânea. São Paulo: UNESP.

Milano, M. S. (2001). Unidades de conservação: técnica, lei e ética para a conservação da biodiversidade. In: Benjamin, A. H. (Org.). Direito ambiental das áreas protegidas: o regime jurídico das unidades de conservação. Rio de Janeiro: Forense Universitária.

Morsello, C. (2001). Áreas protegidas públicas e privadas: seleção e manejo. São Paulo: Annablume; Fapesp.

Observatório das Unidades de Conservação - OBSERVATORIO DAS UCS. (2015). Dados das Unidades de Conservação. Recuperado em 16 de fevereiro, 2015, em http://observatorio.wwf.org.br/.

Pádua, J. A. (2004). Um sopro de destruição: pensamento político e crítica ambiental no Brasil escravista, 1786-1888. Rio de Janeiro: Jorge Zahar.

Schenini, P. C., Costa, A. M. \& Casarin, V. W. (2004). Unidades de Conservação: aspectos históricos e sua evolução. In: Anais do Congresso Brasileiro De Cadastro Técnico Multifinalitário, 6, Florianópolis. COBRAC.

Siebert, C. F. (1997). Estruturação e desenvolvimento da rede urbana do Vale do Itajaí. Blumenau: FURB.

Singer, P. (1998). Ética prática. São Paulo: Martins Fontes.

Sistema Nacional de Unidades de Conservação - SNUC. (2000). Lei n. 9.985, de 18 de julho de 2000. In: Série Cadernos da Reserva da Biosfera. Cad.18. Editor: Conselho Nacional da Reserva da Biosfera.

Vianna, L. P. (2008). De invisíveis a protagonistas: populações tradicionais e unidades de conservação. São Paulo: Annablume, FAPESP.

Vitali, M. \& Uhlig, V. M. (2010). Unidades de Conservação de Santa Catarina. Revista Sustentabilidade em Debate, Brasília, v. 1, n. 1, p. 43-61. 